\title{
O LETRAMENTO CRÍTICO E A FORMAÇÃO DO PROFESSOR-CIDADÃO: CAMINHOS POSSÍVEIS PARA A TRANSFORMAÇÃ̃ DA PRÁTICA E DA POSIÇÃO DOCENTES
}

\author{
Critical Literacy and the Citizen Teacher Education: possible ways for the transformation of \\ teachers' practice and position
}

\author{
Leina JUCÁ (UFOP), Alessandra H. B. FUKUMOTO (UFOP), Andreia ROCHA (UFOP)
}

\begin{abstract}
RESUMO: A busca por possíveis caminhos que proporcionassem a transformação de práticas de ensino e aprendizagem de línguas motivou um grupo de professoras (inglês, italiano, libras, português como segunda língua) a se reunir para repensar suas práticas docentes e a formação de seus alunos. O Letramento Crítico foi a mola propulsora desse grupo que, desde o primeiro semestre de 2011, se encontra semanalmente para discutir, refletir e compartilhar meios que propiciem a formação de cidadãos críticos capazes de estabelecer relações entre língua, cidadania, cultura, práticas sociais e formação de professores. Neste relato, buscamos compartilhar os resultados das discussões advindas de nossos encontros, procurando mostrar como nos reposicionamos em relação à docência e como esse resposicionamento tende a interferir e modificar nossas práticas docentes.
\end{abstract}

PALAVRAS-CHAVE: letramento crítico; formação de professores; ensino e aprendizagem de línguas; cidadania.

\begin{abstract}
The search of possible ways to provide the transformation of language learning and teaching practices led a group of language teachers (English, Italian, Brazilian Sign Language, Portuguese as a Second Language) to get together to rethink their teaching practices and their students' education. Critical Literacy was the driving force of this group, which from the first half of 2011, meets weekly to discuss relationships between language, citizenship, culture, social practices and teacher education. In this report, we seek to share the results of the discussions arising from our meetings, trying to show how we have been repositioning ourselves in relation to teaching and how this repositioning tends to interfere and change our teaching practices.
\end{abstract}

KEY WORDS: critical literacy; teacher education; language teaching and learning; citizenship.

Apresentamo-nos aqui, professoras de diferentes línguas, para diferentes públicos, em diferentes contextos, unidas, porém, por um objetivo em comum: encontrar meios de modificar as nossas práticas docentes, de forma que ensinar e aprender língua faça sentido para nós e para nossos alunos e ultrapasse a condição de ensinar e aprender a língua apenas para fins utilitários (como passar em exames seletivos, conseguir um "bom" emprego, etc.) ou lingüísticos e/ou instrumentais (língua como instrumento de comunicação). Entendemos, desse modo, fazer sentido aquilo que as 


\section{DOSSIÊ ESPECIAL \\ JORDÃO (org.) Letramentos e Multiletramentos no Ensino de Línguas e Literaturas. \\ Revista X, vol.1, 2011}

OCEM (2006) apontam como objetivo do ensino de língua estrangeira na educação formal, ou seja, o ensino para além de aspectos lingüísticos, com objetivos educacionais, sociais e culturais, não apenas como instrumento de comunicação.

Em nosso universo de atuação e formação, nos parece que uma educação de qualidade para todos seja o que está, implícita ou explicitamente, posto como meta nas políticas públicas de educação no Brasil (BRASIL, 2002; MENEZES DE SOUZA; MONTE MOR, 2006; BRASIL, 2011) e nos perguntamos o que viria a ser uma educação de qualidade, como essa educação de qualidade estaria relacionada ao ensino e aprendizagem de línguas e como realizá-la em sala de aula. Seria a qualidade resultante das nossas formações? Ou seria ela resultante das nossas práticas pedagógicas, das nossas crenças, das nossas compreensões acerca do universo escolar? Seria o livro didático (finalmente também disponibilizado para as línguas estrangeiras) a mola propulsora dessa qualidade? Estaria essa qualidade relacionada ao desenvolvimento da cidadania, visto ser essa uma proposta enfatizada pelos documentos oficiais? Mas o que seria, então, a cidadania e como contribuir para formar um cidadão por meio da língua?

De acordo com GENTILI (1999), o conceito de qualidade no campo educacional deve ser compreendido não como empregado por neoconservadores e neoliberais - visão mercadológica, que acaba servindo aos setores hegemônicos, às "minorias satisfeitas", como mecanismo de dualização social e diferenciação. Para o autor não existe qualidade se há discriminação e desigualdade. Dessa forma, qualidade para poucos não é qualidade, mas privilégio. Assim sendo, acreditamos, como mostra o autor, que se faz necessária uma ruptura desta "retórica da qualidade mercadológica" - na qual a educação acaba sendo tratada e abordada como qualquer mercadoria, o que estabelece uma distribuição seletiva e acesso diferenciado - de maneira a conquistar e impor novos sentidos, "um sentido que leve a qualidade ao status de direito inalienável que corresponde à cidadania, sem nenhum tipo de restrição ou segmentação de caráter mercantil” (op.cit.:172), possibilitando às maiorias excluídas da sociedade o direito "a uma educação radicalmente democrática" (op.cit.:177). A articulação da cidadania com a democracia parte da questão do acesso à equidade, entendida como "uma combinação de igualdade formal perante a lei com igualdade de oportunidades" (FALEIROS, 2007: 154-155). Os autores parecem, portanto, apontar na mesma direção já sinalizada pelos documentos oficiais, enfatizando a necessidade de entendermos que só é possível falarmos em educação de qualidade quando todos estão implicados.

De volta ao nosso universo de atuação, contudo, ao observarmos as nossas salas de aula, é inevitável nos questionarmos: estariam aqueles que fazem parte de nossa realidade escolar realmente incluídos naqueles todos para os quais acreditamos deva se destinar uma educação de qualidade? 
Será que nesse todos estariam incluídos aqueles (sejam professores, alunos, formadores, licenciandos) vinculados à Língua Inglesa, e que, historicamente, têm ocupado um lugar pouco privilegiado na escola? Estariam incluídos aqueles com algum tipo de necessidade educativa especial (seja essa auditiva, visual, motora ou mental)? Estariam incluídos os amantes, aqueles que apenas e simplesmente se interessam e se encantam pela língua e pela cultura do outro? Estariam incluídas as crianças e as pessoas idosas, as mulheres, os negros e os pobres? Estariam incluídos os nossos alunos, os supervisores e diretores? Será que nós, professores, estaríamos incluídos?

Com base nessas inquietações, podemos compreender a ênfase que tem sido dada ao caráter educacional da língua estrangeira (BRASIL, 2002; MENEZES DE SOUZA; MONTE MÓR, 2006; BRASIL, 2011), pois esse está, segundo Menezes de Souza e Monte Mór (2006), diretamente relacionado ao conceito de cidadania como um valor social a ser desenvolvido por meio de todas as disciplinas escolares incluindo-se as línguas estrangeiras.

Ser cidadão, segundo esses autores (2006: 91), envolve compreender "que posição/lugar uma pessoa (o aluno, o cidadão) ocupa na sociedade. Ou seja, de que lugar ele fala na sociedade? Por que essa é a sua posição? Como veio parar ali? Ele quer estar nela? Quer mudá-la? Quer sair dela? Essa posição o inclui ou o exclui de quê?". Além disso, a formação de cidadãos envolve, ainda, “a aquisição de conhecimentos e habilidades, assim como a formação de atitudes e valores essenciais ao adequado convívio social". O cidadão é, portanto, alguém capaz de "estabelecer julgamentos, tomar decisões e atuar criticamente frente às questões que a sociedade, a ciência, a tecnologia, a cultura e a economia têm colocado ao presente e, certamente, colocarão ao futuro". (BRASIL, 2011:35). Dessa forma, na perspectiva da chamada "cidadania participativa", que, segundo MATTOS (2011), vai além da noção tradicional de cidadania que envolvia os direitos e deveres do cidadão em relação às leis de um país, "é preciso, acima de tudo, possuir os meios para participar efetivamente e produtivamente na sociedade" (op.cit.: 201) e segundo BRYDON ${ }^{1}$ (2009, apud Mattos, 2011:200): “essas formas renovadas de cidadania requerem habilidades de pensamento crítico altamente desenvolvidas".

Contudo, embora as propostas e diretrizes pareçam sinalizar os caminhos para as mudanças que buscamos, em que possamos andar cada vez mais em direção à qualidade e não ao privilégio, ainda permanecem diversas dúvidas acerca de como essas propostas se relacionam com as nossas salas de aula e com as nossas práticas pedagógicas diárias. Perguntamo-nos pelos meios que, como professoras, podemos utilizar para viabilizar o ensino que enfatize o caráter educacional da língua e a 


\section{DOSSIÊ ESPECIAL \\ JORDÃO (org.) Letramentos e Multiletramentos no Ensino de Línguas e Literaturas. \\ Revista X, vol.1, 2011}

formação de cidadãos e nos tire, talvez, a sensação de que nosso trabalho não faz sentido.

Em nossas buscas por respostas para as nossas dúvidas, vimo-nos diante do que parecia uma possibilidade: um grupo de estudos ${ }^{2}$ sobre Letramento Crítico. Entendemos, hoje, que as razões para estarmos ali reunidas e as expectativas iniciais não estivessem muito claras para muitas das pessoas que se interessaram em participar do grupo naquele primeiro momento. Pensávamos em encontrar caminhos que pudessem nos ajudar a, se não responder em definitivo nossas questões, ao menos trilhar novas possibilidades de práticas educacionais. Mas não sabíamos ao certo o que vinha a ser Letramento Crítico e nos perguntávamos como funcionaria, quais seriam as técnicas, métodos, "receitas" do como fazê-lo. Na verdade, as razões pelas quais o Letramento Crítico nos pareceu um meio de conseguirmos respostas para as nossas dúvidas têm ficado cada vez mais evidentes, na medida em que nossos estudos, discussões e reflexões avançam.

Vimos a nós mesmas e a nossa busca descritas, por exemplo, nas explicações de Mattos \& Valério (2010) segundo as quais, para o Letramento Crítico, o aluno aprende língua "para transformar a si mesmo e a sociedade, se assim lhe convier [...] e ela [a língua] é, em última análise, um instrumento de poder e de transformação social". Transformar-nos e transformar nossas aulas e nossos alunos era o que, afinal, queríamos e o que queremos.

Como professoras de línguas, compreendemos que o ensino de línguas propicia, por sua natureza, o contato com o outro, com o diferente: a outra cultura, os outros costumes, a outra língua. O Letramento Crítico nos mostra como nós, docentes, podemos ir além da mediação entre culturas, línguas e costumes, pois ensinar uma língua não se resume apenas a ensinar um meio de comunicação ou de expressão. Ensinar uma língua é possibilitar ao aluno que ele enxergue o outro, que ele compreenda o que para ele é diferente, é compreender que as diferenças - e, consequentemente a exclusão e o preconceito com o diferente - fazem parte de construções sociais e culturais e que elas podem ser revistas e questionadas. A língua estrangeira é um espaço em que o aluno pode constituir uma "nova identidade", podendo repensar suas crenças e questionar o que lhe foi "ensinado" em sua própria língua materna, pois a língua, inclusive a estrangeira, é construída socialmente. Além disso, não podemos esquecer que o docente também precisa lidar com outro tipo de mediação na sala de aula que vai além daquela entre línguas e culturas: a mediação das relações sociais na sala de aula, que também contribuem para o conhecimento do outro e a compreensão das diferenças. Temos, portanto, nas aulas de língua, um ambiente ideal para que possamos auxiliar os nossos alunos na sua formação crítica, fazendo-os questionar as vozes que se impõem (em todos os

$2 \quad$ O grupo de estudos mencionado nesse trabalho é parte integrante do Projeto Nacional Formação de professores nas teorias dos novos letramentos e multiletramentos: o ensino crítico de línguas estrangeiras na escola, coordenado pelos professores Walkyria Monte Mór e Lynn Mário Menezes de Souza, da Universidade de São Paulo (USP). 
campos sociais de nossas vidas), questionar as diferenças e as formas como essas diferenças são produzidas. (FUKUMOTO, 2010). Essa visão vem ao encontro daquilo que, segundo MCLAUGHLIN; DEVOOGD (2004), seria o foco do Letramento Crítico: a questão do poder, em que se promove o questionamento de quem fala e de onde fala, instigando a reflexão, a transformação e a ação.

Como podemos, então, auxiliar no processo de formação de cidadãos críticos, que posteriormente utilizarão essa criticidade em outras esferas de sua vida? Como lidar com as questões de identidade e diferença na sala de aula? Como essas questões afetam a visão que temos de nossa prática docente? A quais consequências estamos sujeitos a partir dessas práticas? O que vislumbramos a partir dessa nova perspectiva?

A reflexão advinda de um grupo tão heterogêneo permite-nos aos poucos responder essas questões: não existem técnicas, métodos e/ou receitas mágicas. Diante de discussões teóricas e relatos de nossas práticas pedagógicas, podemos perceber que, embora sejamos professoras de áreas distintas, as angústias, as dúvidas e as nossas ansiedades são as mesmas. Nesse momento em que nos identificamos com o outro - o professor - conseguimos refletir com maior clareza sobre a nossa própria prática docente.

Antes do contato com o grupo de estudos sobre Letramento Crítico, algumas de nós se centravam no papel do professor como mediador das relações sociais em sala de aula e a língua era colocada como uma ferramenta que auxiliaria na ruptura de preconceitos e estereótipos, resgatando as diferenças. A abordagem era feita de forma muito pontual: "quebrar estereótipos e preconceitos referentes a um grupo específico de alunos nas aulas de língua". As práticas de Letramento Crítico vêm justamente mostrar-nos que é possível despertar a criticidade do aluno a tal ponto que os questionamentos se estenderão para outras esferas de suas vidas, colaborando para o respeito ao que é “diferente” e a conseqüente ruptura com os estereótipos, pois a questão é: “diferente de quem?” e “quem decide o que é 'diferente'?”.

No que diz respeito ao ensino-aprendizagem de língua, parecia - e ainda parece - a algumas de nós, na condição de alunas e, posteriormente, de professoras, que não fazia - e ainda não faz sentido algum ensinar e aprender a língua pela língua, apenas por seu caráter instrumental. Em nosso universo de atuação e formação, já acreditamos, por exemplo, que a língua comunicasse as ideias e valores que acreditávamos fossem os nossos e não pensávamos que fosse, pela língua, a criação (e não apenas a comunicação) dessas idéias e valores. Já acreditamos que a língua fosse neutra - e a língua, quando estrangeira, parece mais forte, por diversas razões, em ajudar-nos a alimentar essa ingenuidade -, que ela, assim como proposta em materiais e livros didáticos, em programas e bolsas 
de estudo no exterior, não carregasse além daquilo que ali estava colocado "explicitamente". Já acreditamos que a língua fosse uma só, independentemente de seus usuários ou contextos sóciohistórico-culturais (LIMA 3 , 2006 apud MATTOS, 2011). Hoje, tendemos a acreditar que abandonamos um tanto da ingenuidade do passado e nos demos a oportunidade de ter novas visões, novas leituras do mundo em que vivemos e, consequentemente, passamos a ter a chance de ocupar novos lugares, seja como alunas, professoras, supervisoras, diretoras ou formadoras. Nosso reposicionamento está em construção.

Estamos em um momento de reconstrução e reconstruir implica trabalhar com o novo que se apresenta a nós e implica, portanto, em desvincular-se e/ou readaptar o velho que nos acompanha desde o início da nossa formação, ou seja, as velhas práticas pedagógicas enraizadas no ensino e aprendizagem da língua, sem a preocupação em se estabelecer relações entre língua e visões de mundo. Não há mais como ignorar a responsabilidade política que temos como educadoras. Compreendemos hoje que todo discurso é uma representação da realidade, moldada pelas práticas sociais, pelas relações de poder, pelo interesse de cada um. Trabalhar de forma crítica implica estar ciente dessas representações que se encontram embutidas nos textos. Na perspectiva do Letramento Crítico, o indivíduo deve estar preparado para agir dentro e sobre seu contexto local e global, com vistas a uma sociedade mais justa e democrática. Usamos a língua como meio transformador e estamos aprendendo a enxergar as coisas de diferentes perspectivas, a compreender que não existem conceitos estáticos e nem verdades absolutas (POZZO, 2010).

O Letramento Crítico não nos conduz apenas a uma abordagem metodológica que busca desenvolver a capacidade crítica dos alunos, mas também ao desenvolvimento dessa capacidade em nós professores. Será que estamos preparados para utilizar em nossas aulas uma prática pedagógica voltada a contribuir para a formação de um cidadão crítico? Nossos encontros oportunizam essa reflexão e, tanto a diversidade de relatos como a experiência de cada uma de nós, enriquece a construção desse conhecimento, em que teoria e prática são um continuum e , portanto, caminham juntas, jamais desvinculadas.

\section{REFERÊNCIAS}

BRASIL/SEMTEC. PCN+ Ensino Médio: Orientações educacionais complementares aos Parâmetros Curriculares Nacionais. Volume 1: Linguagens, códigos e suas tecnologias. Brasília, DF: 2002. Disponível em: <http://portal.mec.gov.br/seb/arquivos/pdf/02Linguagens.pdf >. Acesso em: 30/09/2011.

LIMA, C. A brief introduction to critical literacy in English language education. Brasília: ELTECS/British Council Brazil/CSSGJ (University of Nottingham), 2006. Disponível em: 〈http://www.criticalliteracy.org.uk/elt〉. Acesso em: 3 fev. 2008. 
BRASIL. PNLD 2011: Edital de Convocação para Inscrição no Processo de Avaliação e Seleção de Coleções Didáticas para o Programa Nacional do Livro Didático - MEC/FNDE - Secretaria de Educação Básica. Disponível em:

$<$ http://www.abrale.com.br/Edital\%20PNLD\%202011.pdf >. Acesso em: 12/11/2011.

FALEIROS, Vicente de Paula. "Cidadania : os idosos e a garantia de seus direitos". In: NERI, Anita Liberalesso (org.). Idosos no Brasil : vivências, desafios e expectativas na terceira idade. São Paulo: Ed. Fundação Perseu Abramo; Edições SESC-SP, 2007. p. 153-168.

FUKUMOTO, Alessandra H. B. O ambiente intergeracional no ensino de italiano LE: o caso do Italiano no Campus. 2010. 355 f. Dissertação (Mestrado) - Faculdade de Filosofia, Letras e Ciências Humanas, Universidade de São Paulo, São Paulo.

GENTILI, Pablo A. A. "O discurso da 'qualidade' como nova retórica conservadora no campo educacional". In: GENTILE, Pablo A. A.; SILVA, Tomaz Tadeu da. Neoliberalismo, qualidade total e educação : visões críticas. Petrópolis: Vozes, 1999. p. 111-177.

MATTOS, A. M. A. O Ensino de Inglês como Língua Estrangeira na Escola Pública: Novos Letramentos, Globalização e Cidadania. 2011. 248 f. (Doutorado) - Programa de Pós-Graduação em Estudos Linguísticos e Literários em Inglês, Faculdade de Filosofia, Letras e Ciências Humanas, Universidade de São Paulo.

MATTOS, A. M. A.; VALÉRIO, K. M. Letramento crítico e ensino comunicativo: lacunas e interseções. Revista Brasileira de Linguística Aplicada, v. 10, n. 1, p. 135-158, 2010.

MCLAUGHLIN, Maureen; DEVOOGD, Glenn L. "Becoming critically aware". In: Critical Literacy : Enhancing students' comprehension of text. Scholastic : New York, 2004. p. 13-33.

MENEZES DE SOUZA, L. M. \& MONTE MOR, W. (2006) Orientações Curriculares para o Ensino Médio: Línguas Estrangeiras. In: Linguagens, Códigos e Tecnologias. Brasilia: MEC. Disponível em: <http://portal.mec.gov.br/seb/arquivos/pdf/book_volume_01_internet.pdf > Acesso em: 30/09/2011.

POZZO, Bryan Rafael Dall. (2010) Estudos do Letramento: Discussão de Conceitos. Programa de Educação Tutorial - $\quad$ Letras Unicentro. Disponível em: <http://web03.unicentro.br/pet/pdf/2010/Artigo_BRYAN_PET_2010.pdf $>$. Acesso em: 30/09/2011. 